Title

\title{
Effect of 'Late-harvest' of Hops (Humulus lupulus L.) on The Contents of Volatile Thiols in Furano Beauty, Furano Magical, and Cascade Varieties
}

\section{Authorship}

Mitsuhiro Uemoto (1)* Kiyoshi Takoi(2), Atsushi Tanigawa(2), Koji Takazumi(3), Kensuke Ogushi

(1), Koichiro Koie (1), Narushi Suda (4)

${ }^{1}$ Crop Research Laboratories, SAPPORO BREWERIES LTD., 3-5-25 Motomachi, Kamifurano, Sorachi, Hokkaido, 071-0552 Japan

${ }^{2}$ Product \& Technology Innovation Department, SAPPORO BREWERIES LTD., 10 Okatome, Yaizu, Shizuoka, 425-0013 Japan

${ }^{3}$ Frontier Laboratories for Value Creation, SAPPORO BREWERIES LTD., 10 Okatome, Yaizu, Shizuoka, 425 -0013

Japan

${ }^{4}$ Crop Research Laboratories, SAPPORO BREWERIES LTD., 37-1 Nittakizaki, Ota, Gunma, 3700321 Japan

*Corresponding author: TEL. +81-167-45-2040

E-mail: Mitsuhiro.Uemoto@sapporobeer.co.jp 


\section{Supplementary infomations}

\section{Method: Sensory evaluation using hop water extraction by boiling (HWEB)}

Sensory evaluation of hop cone is done using HWEB as reported by Koie et al., 2016. The details are as follows. Ground hop cone, i.e., hop powder, and $200 \mathrm{~mL}$ of distilled water were added to a $300 \mathrm{~mL}$ glass flask. The amount of hop powder was adjusted to $0.5 \mathrm{~g}$ of $\alpha$ acids/L. The flask was capped with aluminum foil. The flask was then autoclaved at $105{ }^{\circ} \mathrm{C}$ for $5 \mathrm{~min}$. After the temperature decreased to $80{ }^{\circ} \mathrm{C}$, the flask was removed from the autoclave vessel and cooled in ice-water for at least $10 \mathrm{~min}$. After cooling, the aqueous mixture of hop powder and water was filtered using filter paper. $20 \mathrm{ml}$ of filtrate was added to brown glass vessels and used for sensory evaluation tests. The sensory panel consisted of six people, all males aged between 25 and 65 years old. The nine criteria ("Hay", "Tea", "Woody", "Citrus", "Grape/Currant", "Flower/Fruits", "Green", "Spicy/Herbal", and "Bouillon") were scored from 0 (no flavor) to 4 (strong flavor) at intervals of 0.5 . The mean intensity value of each characteristic was calculated, and paired t-tests were conducted in Microsoft Excel 2013.

\section{Results: Sensory evaluation of hop cones using hop water extraction by boiling (HWEB)}

To evaluate the sensory profile of the hop cones, HWEB was conducted on samples of Furano Beauty and Furano Magical harvested in 2015 (Supplementary Figure 1). DAF 65 sample of Furano Beauty had higher scores for "Grape/Currant" and "Fruit/Flower" characters in comparison with DAF 45 sample of the variety. DAF 65 sample of Furano Magical had lower scores for "Citrus" and 
"Fruit/Flower" characters but had a higher score of "Grape/Currant" character in comparison with the DAF 45 sample. All observed differences in scores were as not statistically significant. However, in both varieties, flavor profiles of HWEB showed a large discrepancy between normal-harvest and lateharvest. Inui et al. also reported that the sensory evaluation scores of floral, fruity and citrusy characters were significantly increased with a delay in the harvest date of hops. ${ }^{27}$ These results suggested that the flavor profiles of hops could change by late-harvesting.

\section{Method: Analysis of Terpenoids by Headspace-Solid Phase Microextraction-Gas}

\section{Chromatography-Mass Spectrometry (HS-SPME-GC-MS).}

The quantitation of terpene alcohols, aldehydes, esters, and hydrocarbons was conducted on a 7890B GC with a 5977A MS (Agilent Technologies). $8 \mathrm{ml}$ of each beer sample was placed in a $20 \mathrm{~mL}$ glass vial with $3 \mathrm{~g}$ of sodium chloride, followed by spiking with $40 \mu \mathrm{L}$ of $10 \mathrm{mg} / \mathrm{L}$ benzyl acetate as the internal standard. The vial was hermetically sealed with a magnetic cap and agitated at $50{ }^{\circ} \mathrm{C}$ for 30 min on a Combi-PAL system (CTC Analytics). The SPME fiber (PDMS/DVB [polydimethylsiloxane/divinylbenzene], $65 \mu \mathrm{m}$ film thickness, Supelco, Bellefonte, PA) was inserted into the head space of the vial and held at $50^{\circ} \mathrm{C}$ for $15 \mathrm{~min}$ for adsorption. After adsorption, the SPME fiber was immediately inserted into a GC injector for thermal desorption for $3 \mathrm{~min}$ at $270{ }^{\circ} \mathrm{C}$. tThe separation of volatiles was performed on a HP-1MS column $(30 \mathrm{~m} \times 0.25 \mathrm{~mm}$ i.d., $1 \mu \mathrm{m}$ film thickness; aAgilent Technologies) with a helium carrier gas at a constant flow rate of $1.0 \mathrm{~mL} / \mathrm{min}$. The oven 
temperature setting was as follows: $40^{\circ} \mathrm{C}$ for $3 \mathrm{~min}$, raised to $200{ }^{\circ} \mathrm{C}$ at a rate of $5{ }^{\circ} \mathrm{C} / \mathrm{min}$, and raised to $320^{\circ} \mathrm{C}$ at a rate of $10^{\circ} \mathrm{C} / \mathrm{min}$. Calibration curves were constructed using the beer samples spiked with reference compounds. An appropriate range of the calibration curves was determined for calculating the concentrations of the compounds in sample beers. The monitored ions, range of the calibration curve, and the ratios of the isomers in the reference compounds are listed in Supplementary Table 1. All calibrations produced a linear correlation with an $\mathrm{R}^{2}$ value $>0.99$, across the entire concentration range analyzed. All tests were run twice to reduce error. The data of terpenoids in sample beers are shown in Supplementary Table 2.

\section{Method: Determination of the Ratio of Isomers in the Reference Compounds by GC-FID.}

Among the reference compounds, citral and methyl geranate contained isomers. It is well-known that citral is a mixture of geranial and neral, and commercial methyl geranate reagent contained small amounts of methyl nelorate. All the reference compounds contained small amounts of contaminants and/or degradation products. For isomer analysis, GC-FID measurements were conducted on a 6890N gas chromatograph (Agilent Technologies). The carrier gas was helium with a flow rate of $1.7 \mathrm{~mL} / \mathrm{min}$ in the constant-flow mode. The detector used was a flame-ionization detector at $250^{\circ} \mathrm{C}$. Hydrogen gas at a flow rate of $40 \mathrm{~mL} / \mathrm{min}$ and air at $450 \mathrm{~mL} / \mathrm{min}$ were used for the FID. Aliquots $(1 \mu \mathrm{L})$ of each chemical $(500 \mathrm{mg} / \mathrm{L})$ were injected into a split injector $\left(250^{\circ} \mathrm{C}\right.$; split rate, $100: 1$; purge flow, 168.5 $\mathrm{mL} / \mathrm{min})$ at an oven temperature of $50{ }^{\circ} \mathrm{C}$ onto a type HP-INNOwax capillary column $(30 \mathrm{~m} \times 0.25$ 
mm i.d., $0.25 \mu \mathrm{m}$ film thickness; Agilent Technologies). For all measurements, the temperature program was as follows: $50{ }^{\circ} \mathrm{C}$ for $2.5 \mathrm{~min}$, heated at $10{ }^{\circ} \mathrm{C} / \mathrm{min}$ to $240{ }^{\circ} \mathrm{C}$, and a $5 \mathrm{~min}$ isotherm. The ratio isomers and contaminants was calculated on the basis of the areas of all the peaks obtained using the FID detector. The calculated isomer ratios are listed in Supplementary Table 1. 
Furano Beauty

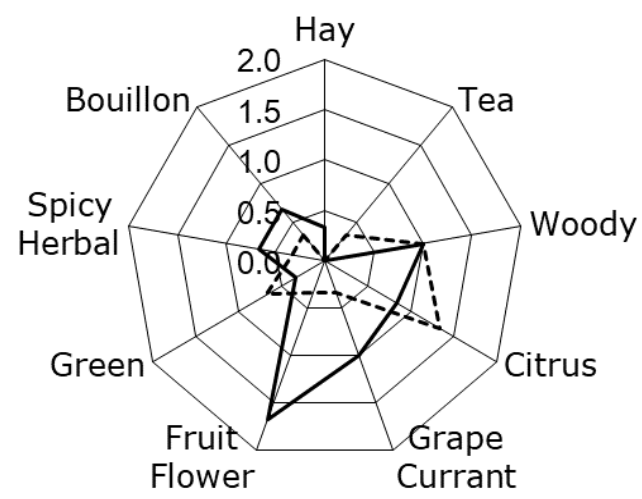

Furano Magical

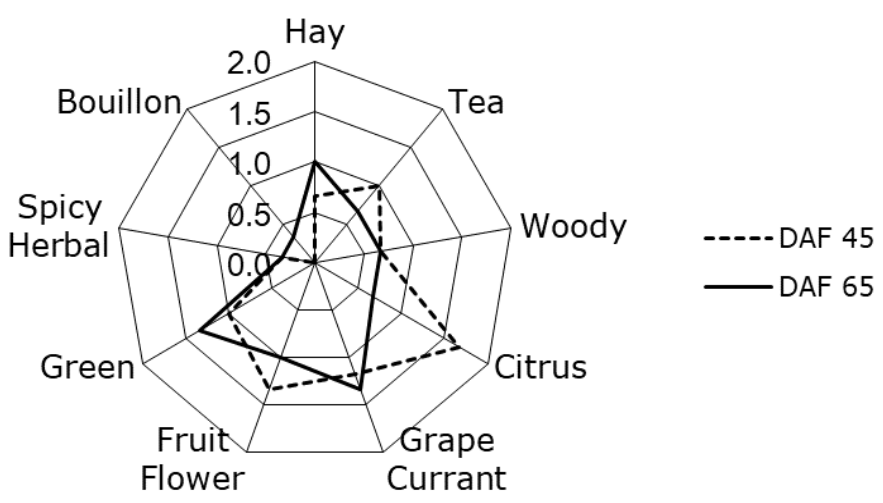

Supplementary Figure 1. Sensory profiles of hop water extraction by boiling using hop cones of

Furano Beauty and Furano Magical harvested in 2015; DAF, days after flowering. 
Supplementary Table 1. GC-MS parameters for quantitation of selected flavor compounds.

\begin{tabular}{|c|c|c|c|c|c|}
\hline group & compound & isomers & $\begin{array}{l}\text { ratio of } \\
\text { isomers }\end{array}$ & $\begin{array}{l}\text { target ion } \\
(\mathrm{m} / \mathrm{z})\end{array}$ & $\begin{array}{l}\text { qualification ion } \\
(\mathrm{m} / \mathrm{z})\end{array}$ \\
\hline \multirow{5}{*}{ alcohols } & linalool & & - & 136 & 121 \\
\hline & $\alpha$-terpineol & & - & 136 & 121 \\
\hline & $\beta$-citronellol & & - & 138 & 109 \\
\hline & geraniol & & - & 136 & 121 \\
\hline & nerol & & - & 121 & 93,69 \\
\hline \multirow{2}{*}{ aldehydes } & \multirow{2}{*}{ citral } & geranial & 0.53 & 152 & 137 \\
\hline & & neral & 0.27 & 137 & 119 \\
\hline \multirow{2}{*}{ esters } & \multirow{2}{*}{ metyl geranate } & methyl geranate & 0.72 & 114 & 182 \\
\hline & & methyl nerolate & 0.29 & 114 & 182 \\
\hline \multirow{5}{*}{ hydrocarbons } & $\alpha$-terpinene & & - & 136 & 121 \\
\hline & $\gamma$-terpinene & & - & 136 & 121 \\
\hline & (+)-limonene & & - & 136 & 121 \\
\hline & terpinolene & & - & 136 & 121 \\
\hline & myrcene & & - & 93 & 69 \\
\hline
\end{tabular}


Supplementary Table 2. Concentrations of terpenoids in the trial beers.

\begin{tabular}{|c|c|c|c|c|c|}
\hline & & \multicolumn{2}{|c|}{ Furano Beauty } & \multicolumn{2}{|c|}{ Furano Magical } \\
\hline & & DAF 45 & DAF 65 & DAF 45 & DAF 65 \\
\hline \multirow{5}{*}{ alcohols } & linalool $(\mu \mathrm{g} / \mathrm{L})$ & 71.6 & 137 & 92.4 & 152 \\
\hline & $\alpha$-terpineol $(\mu \mathrm{g} / \mathrm{L})$ & 3.7 & 4.8 & 4.0 & 5.4 \\
\hline & $\beta$-citronellol ( $\mu \mathrm{g} / \mathrm{L})$ & 11.2 & 8.5 & 8.2 & 5.8 \\
\hline & geraniol $(\mu \mathrm{g} / \mathrm{L})$ & 20.6 & 25.4 & 19.5 & 15.7 \\
\hline & $\operatorname{nerol}(\mu \mathrm{g} / \mathrm{L})$ & 2.6 & 2.7 & 2.1 & 3.0 \\
\hline \multirow{2}{*}{ aldehydes } & geranial $(\mu \mathrm{g} / \mathrm{L})$ & 0.4 & 0.5 & 0.6 & 0.5 \\
\hline & $\operatorname{neral}(\mu \mathrm{g} / \mathrm{L})$ & n.d. & n.d. & n.d. & n.d. \\
\hline \multirow{2}{*}{ esters } & methyl geranate $(\mu \mathrm{g} / \mathrm{L})$ & 7.5 & 19.1 & 7.7 & 15.9 \\
\hline & methyl nerolate $(\mu \mathrm{g} / \mathrm{L})$ & 0.1 & 0.3 & $\operatorname{tr}$ & 0.1 \\
\hline \multirow{5}{*}{ hydrocarbons } & $\alpha$-terpinene $(\mu \mathrm{g} / \mathrm{L})$ & 0.1 & 0.2 & 0.2 & 0.3 \\
\hline & $\gamma$-terpinene $(\mu \mathrm{g} / \mathrm{L})$ & $\operatorname{tr}$ & $\operatorname{tr}$ & $\operatorname{tr}$ & $\operatorname{tr}$ \\
\hline & $(+)$-limonene $(\mu \mathrm{g} / \mathrm{L})$ & 0.1 & 0.1 & 0.1 & 0.2 \\
\hline & terpinolene $(\mu \mathrm{g} / \mathrm{L})$ & 0.1 & 0.1 & 0.1 & 0.1 \\
\hline & myrcene $(\mu \mathrm{g} / \mathrm{L})$ & 0.9 & 6.1 & 1.3 & 3.8 \\
\hline
\end{tabular}

DAF, days after flowering; n.d., not detected; tr, trace. 